14. Abramsson, A., et al. 2002. Analysis of mural cell recruitment to tumor vessels. Circulation. 105:112-117.

15. Benjamin, L.E., Golijanin, D., Itin, A., Pode, D. and Keshet, E. 1999. Selective ablation of immature blood vessels in established human tumors follows vascular endothelial growth factor withdrawal. J. Clin. Invest. 103:159-165.

16. Simon, M.P., et al. 1997. Deregulation of the platelet-derived growth factor B-chain gene via fusion with collagen gene COL1A1 in dermatofibrosarcoma protuberans and giant-cell fibroblastoma. Nat. Genet. 15:95-98.

17. Pietras, K., et al. 2002. Inhibition of PDGF receptor signaling in tumor stroma enhances antitumor effect of chemotherapy. Cancer Res. 62:5476-5484

18. Heuchel, R., et al. 1999. Platelet-derived growth factor beta receptor regulates interstitial fluid homeostasis through phosphatidylinositol-3' kinase signaling. Proc. Natl. Acad. Sci. U. S. A. 96:11410-11415.

19. Coussens, L.M., and Werb, Z. 2002. Inflammation and cancer. Nature. 420:860-867.

20. Luttun, A., et al. 2002. Revascularization of ischemic tissues by PIGF treatment, and inhibition of tumor angiogenesis, arthritis and atherosclerosis by anti-Flt1. Nat. Med. 8:831-840

21. Schoppmann, S.F., et al. 2002. Tumor-associated macrophages express lymphatic endothelial growth factors and are related to peritumoral lymphangiogenesis. Am. J. Pathol. 161:947-956 22. Yancolpoulos, G.D., et al. 2000. Vascular-specific growth factors and blood vessel formation. Nature. 407:242-248.

23. Olofsson, B., et al. 1998. Vascular endothelial growth factor B (VEGF-B) binds to VEGF receptor- 1 and regulates plasminogen activator activity in endothelial cells. Proc. Natl. Acad. Sci.U. S. A. 95:11709-11714.

24. Bergsten, E., et al. 2001. PDGF-D is a specific, protease-activated ligand for the PDGF- $\beta$-receptor. Nat. Cell Biol. 3:512-516.

25. LaRochelle, W.J., et al. 2001. PDGF-D, a new protease-activated growth factor. Nat. Cell Biol. 3:517-521

\title{
Peptide-based treatment for autoimmune diseases: learning how to handle a double-edged sword
}

\author{
Alberto Pugliese \\ Departments of Medicine, and Immunology and Microbiology, Immunogenetics Program, \\ Diabetes Research Institute, University of Miami, Miami, Florida, USA
}

J. Clin. Invest. 111:1280-1282 (2003). doi:10.1172/JCI200318395.

Several self-molecules have been identified as target antigens in autoimmune diseases. Since lack or loss of tolerance to these molecules is one of the key events promoting autoimmunity, researchers are exploring the possibility that the administration of antigens or peptides may stimulate tolerogenic mechanisms and delay or prevent the full phenotypic expression of autoimmune diseases. There is much enthusiasm for such therapies, as these will probably be disease-specific and not associated with the side effects of conventional immunosuppression. Studies have been performed and are ongoing in both rodents and humans,

\footnotetext{
Address correspondence to: Alberto Pugliese, Departments of Medicine, and Immunology and Microbiology, Immunogenetics Program, Diabetes Research Institute, University of Miami, $1450 \mathrm{NW}$

Tenth Avenue, Miami, Florida 33136, USA. Phone (305) 243-5348; Fax: (305) 243-4404;

E-mail: apuglies@med.miami.edu.

Conflict of interest: The author has declared that no conflict of interest exists.

Nonstandard abbreviations used: type 1 diabetes (T1D); glutamic acid decarboxylase (GAD); Diabetes Prevention

Trial-Type 1 (DPT-1).
}

using whole antigens or peptides, and testing diverse administration routes such as intrathymic, intraperitoneal, intravenous, subcutaneous, oral, and intranasal. Despite many studies, robust data demonstrating clinical benefits are not yet available (1).

\section{Antigen and/or peptide-based interventions in diabetes}

Type 1 diabetes (T1D) represents one of the most suitable diseases to exemplify such heterogeneous outcomes. Three autoantigens - proinsulin/ insulin, glutamic acid decarboxylase (GAD), and tyrosine phosphatase-like protein IA-2 (or ICA512) - have been well characterized in both humans and the NOD mouse model of autoimmune diabetes (2). Although all of these molecules are expressed in pancreatic islets, insulin and its precursor proinsulin are uniquely secreted by pancreatic $\beta$-cells. Several studies have suggested an important role for autoimmune responses to epitopes of insulin/proinsulin, such as the peptides B9-23 (the 9-23 amino acid region of the insulin $B$ chain) $(3,4)$ and B24-C36 (the proinsulin B-chain-
C-peptide junction) $(5,6)$. In NOD mice, both subcutaneous and oral administration of insulin can delay or prevent diabetes; oral insulin induces regulatory $\mathrm{CD}^{+}{ }^{+} \mathrm{T}$ cells, while nasorespiratory insulin induces regulatory $\mathrm{CD}^{+} \gamma \delta$-T cells $(7-11)$. However, in a Diabetes Prevention Trial-Type 1 (DPT-1) study that involved the parenteral administration of insulin, no significant effect on progression to overt disease in autoantibody-positive first-degree relatives of T1D patients, who have increased risk of developing diabetes, was demonstrated (12). While the results of the oral insulin arm of DPT-1 are expected in June 2003, a randomized, crossover, pilot trial of intranasal insulin in at-risk first-degree relatives demonstrated changes in immune and metabolic markers that were consistent with an immunoprotective effect (13).

The subcutaneous or intranasal administration of the insulin peptide B9-23 can also prevent diabetes in NOD mice (3), similarly to the neonatal administration of the B10-24 peptide (9). However, the administration of several antigen-derived peptides, in adjuvant, to newborn NOD mice, resulted in the early activation of multiple autoimmune responses (14). Similarly, the intrathymic injection of T1D-associated antigens or peptides resulted in delayed or accelerated diabetogenesis, depending on the peptides used (15). Recent studies in mice have also shown that the repeated administration of insulin or GAD peptides, including the B9-23 peptide, can induce lethal anaphylactic responses $(16,17)$. While similar occurrences have not been reported in a phase I trial in which a modified insulin B9-23 peptide (altered peptide 


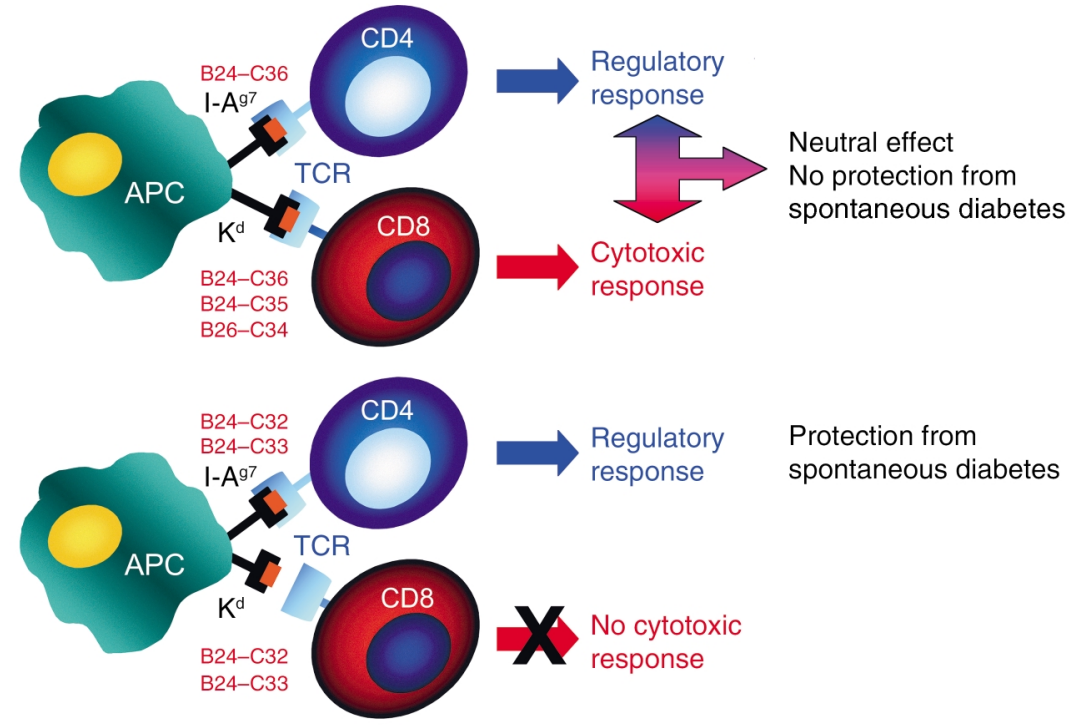

Figure 1

Disabling a $\mathrm{CD}^{+}$epitope. Intranasal administration of different proinsulin peptides results in presentation from an antigen-presenting cell (APC) to $C D 4^{+}$and $C D 8^{+} \mathrm{T}$ cells, depending on the peptide administered. Proinsulin peptides B24-C36, B24-C35, and B26-C34 can bind to the MHC class I molecule $\left(\mathrm{K}^{\mathrm{d}}\right)$, resulting in the activation of cytotoxic T cells. The use of truncated peptides that do not contain the residues critical for binding to $\mathrm{K}^{\mathrm{d}}$, but still bind to the NOD mouse $\mathrm{MHC}$ class II molecule $\left(\mathrm{I}-\mathrm{A}^{\mathrm{g}}\right)$, allows for selective activation of regulatory $\mathrm{CD} 4^{+} \mathrm{T}$ cells. The same APC is shown presenting simultaneously to both $\mathrm{CD} 4^{+}$and $\mathrm{CD} 8^{+}$ T cells for illustration purposes. TCR, T cell receptor.

ligand) was administered subcutaneously to normal individuals, the administration of any proinsulin or insulin peptides has not yet been attempted in the context of T1D prevention trials or in an attempt to halt autoimmunity in new onset patients. Clearly, more studies are needed as a number of factors, including the nature of the antigen or peptide, the dose, the route and/or mode of administration, and the stage of disease at which the subjects enter the trial, can all influence the efficacy and safety of these experimental treatments.

\section{The double-edged sword}

In the current issue of the JCI, Martinez et al. report on a new element that will need to be considered when attempting peptide-based T1D therapy (18). While the goal of peptide administration is to induce regulatory cells and inhibit specific autoimmune responses, the data show that, depending on the peptide used, one may also induce undesired cytotoxic $\mathrm{CD}^{+} \mathrm{T}$ cell responses. In this study, the intranasal administration of the $\mathrm{B} 24-\mathrm{C} 36$ proinsulin peptide to NOD mice induced regulatory cells

\section{Table 1}

resulted in both regulatory $\mathrm{CD} 4^{+} \mathrm{T}$ cell and cytotoxic $\mathrm{CD}^{+} \mathrm{T}$ cell responses recognizing the $\mathrm{K}^{\mathrm{d}}$-restricted $\mathrm{B} 25-\mathrm{C} 34 \mathrm{epi}$ tope contained in the B24-C36 peptide. Such cytotoxic responses blunted the protective effect associated with the induction of the regulatory cells, suggesting that mucosal administration of antigen can sometimes be a doubleedged sword. To circumvent this problem, the authors designed a strategy to "disable" the $\mathrm{CD} 8^{+}$epitope contained in the B24-C36 peptide, in other words, to prevent $\mathrm{CD}^{+} \mathrm{T}$ cells from recognizing this epitope, while preserving the ability to induce regulatory $\mathrm{CD}^{+} \mathrm{T}$ cells (Figure 1 and Table 1). This was achieved by treating the mice with truncated peptides, B24-C33 or B24-C32, still capable of binding to $\mathrm{IA}^{\mathrm{g} 7}$ but not to $\mathrm{K}^{\mathrm{d}}$. Intranasal administration of the truncated peptides resulted indeed in a significant reduction in the incidence of spontaneous diabetes.

The findings reported by Martinez et al. (18) suggest that the undetected induction of $\mathrm{CD}^{+} \mathrm{T}$ cell responses could explain at least some of the contrasting outcomes reported by several experimental studies and clinical trials. Most importantly, this study has practical implications for the design of clinical trials based on the administration of peptides for preventing autoimmunity. Based on these findings, it would seem helpful to select putative therapeutic peptides for their ability to selectively bind class II but not class I molecules that are used as restriction elements by $\mathrm{CD}^{+} \mathrm{T}$ cells and could potentially antagonize the beneficial effects of class II-restricted, regulatory $\mathrm{CD}^{+} \mathrm{T}$ cells. This strategy can effectively disable the potential of eliciting cytotoxic responses and maximize the protective effects of the regulatory cells. While this study was limited to the NOD mouse MHC molecules, the availability of mouse strains expressing human class II

Key proinsulin peptides, their respective MHC binding capacities, and induced T cell responses

\begin{tabular}{|c|c|c|c|c|c|c|c|c|c|c|c|c|c|c|c|}
\hline $\begin{array}{l}\text { Proinsulin } \\
\text { Peptides }\end{array}$ & & & & & & & & & & & & & & $\begin{array}{l}\mathrm{I}-\mathrm{A}^{\mathrm{g}} / \mathrm{K}^{\mathrm{d}} \\
\text { Binding }\end{array}$ & $\begin{array}{c}\mathrm{CD}^{+} / \mathrm{CD} 8 \\
\text { Responses }\end{array}$ \\
\hline Residues & 24 & 25 & 26 & 27 & 28 & 29 & 30 & 31 & 32 & 33 & 34 & 35 & 36 & & \\
\hline B24-C36 & $\mathrm{F}$ & $\mathrm{F}$ & $Y$ & $\mathrm{~T}$ & $\mathrm{P}$ & M & $S$ & $\mathrm{R}$ & $\mathrm{R}$ & $E$ & V & $E$ & $\mathrm{D}$ & Yes/Yes & Yes/Yes \\
\hline B24-C33 & $\mathrm{F}$ & $\mathrm{F}$ & $Y$ & $\mathrm{~T}$ & $P$ & M & $S$ & $\mathrm{R}$ & $\mathrm{R}$ & E & - & - & - & Yes/No & Yes/No \\
\hline B24-C32 & $\mathrm{F}$ & $\mathrm{F}$ & $Y$ & T & $\mathrm{P}$ & M & S & $\mathrm{R}$ & $\mathrm{R}$ & - & - & - & - & Yes/No & Yes/No \\
\hline
\end{tabular}


and class I molecules (19-21), in particular those associated with T1D susceptibility, is increasing. This offers researchers the opportunity to test such binding predictions and may provide an in vivo readout of the responses induced by a given peptide also in relation to dose and route of administration. Screening of candidate peptides for clinical trials using such humanized mouse models could guide the choice of peptides for future prevention trials and might maximize our chances of achieving both efficacy and safety.

1. Nepom, G.T. 2002. Therapy of autoimmune diseases: clinical trials and new biologics. Curr. Opin. Immunol. 14:812-815.

2. Liu, E., and Eisenbarth, G.S. 2002. Type 1A diabetes mellitus-associated autoimmunity. Endocrinol. Metab. Clin. North Am. 31:391-410.

3. Daniel, D., and Wegmann, D.R. 1996. Protection of nonobese diabetic mice from diabetes by intranasal or subcutaneous administration of insulin peptide B-(9-23). Proc. Natl. Acad. Sci. U. S. A. 93:956-960.

4. Wong, F.S., et al. 1999. Identification of an MHC class I-restricted autoantigen in type 1 diabetes by screening an organ-specific cDNA library. Nat. Med. 5:1026-1031.

5. Chen, W., et al. 2001. Evidence that a peptide span- ning the B-C junction of proinsulin is an early autoantigen epitope in the pathogenesis of type 1 diabetes. J. Immunol. 167:4926-4935.

6. Rudy, G., et al. 1995. Similar peptides from two beta cell autoantigens, proinsulin and glutamic acid decarboxylase, stimulate T cells of individuals at risk for insulin-dependent diabetes. Mol. Med. 1:625-633

7. Muir, A., Schatz, D., and Maclaren, N. 1993. Antigen-specific immunotherapy: oral tolerance and subcutaneous immunization in the treatment of insulin-dependent diabetes. Diabetes Metab. Rev 9:279-287.

8. Bergerot, I., Fabien, N., Maguer, V., and Thivolet, C 1994. Oral administration of human insulin to NOD mice generates CD4+ T cells that suppress adoptive transfer of diabetes. J. Autoimmun. 7:655-663.

9. Maron, R., Guerau-de-Arellano, M., Zhang, X., and Weiner, H.L. 2001. Oral administration of insulin to neonates suppresses spontaneous and cyclophosphamide induced diabetes in the NOD mouse. J. Autoimmun. 16:21-28.

10. Atkinson, M., Maclaren, N., Luchetta, R., and Burr, I. 1990. Insulitis and diabetes in NOD mice reduced by prophylactic insulin therapy. Diabetes. 39:933-937.

11. Harrison, L.C., Dempsey-Collier, M., Kramer, D.R., and Takahashi, K. 1996. Aerosol insulin induces regulatory CD8 gamma delta $\mathrm{T}$ cells that prevent murine insulin-dependent diabetes. J. Exp. Med. 184:2167-2174.

12. Diabetes Prevention Trial-Type 1 Diabetes Study Group. 2002. Effects of insulin in relatives of patients with type 1 diabetes mellitus. N. Engl. J. Med. 346:1685-1691.
13. Harrison, L.C., et al. 1999. Intranasal insulin trial (INIT) in preclinical type 1 diabetes. Diabetes. 48:A206. (Abstr.)

14. Tian, J., Olcott, A.P., and Kaufman, D.L. 2002 Antigen-based immunotherapy drives the precocious development of autoimmunity. J. Immunol. 169:6564-6569.

15. Cetkovic-Cvrlje, M., et al. 1997. Retardation or acceleration of diabetes in NOD/Lt mice mediated by intrathymic administration of candidate beta-cell antigens. Diabetes. 46:1975-1982.

16. Liu, E., et al. 2002. Anti-peptide autoantibodies and fatal anaphylaxis in NOD mice in response to insulin self-peptides B:9-23 and B:13-23. J. Clin. Invest. 110:1021-1027. doi:10.1172/JCI200215488.

17. Pedotti, R, et al. 2003. Severe anaphylactic reactions to glutamic acid decarboxylase (GAD) self peptides in NOD mice that spontaneously develop autoimmune type 1 diabetes mellitus. BMC Immunol. 4:2

18. Martinez, N.R., et al. 2003. Disabling an integral CTL epitope allows suppression of autoimmune diabetes by intranasal proinsulin peptide. J. Clin. Invest. 111:1365-1371. doi:10.1172/JCI200317166.

19. Das, P., Abraham, R., and David, C. 2000. HLA transgenic mice as models of human autoimmune diseases. Rev. Immunogenet. 2:105-114.

20. Wong, F.S., Moustakas, A.K., Wen, L., Papadopoulos, G.K., and Janeway, C.A., Jr. 2002. Analysis of structure and function relationships of an autoantigenic peptide of insulin bound to $\mathrm{H}-2 \mathrm{~K}(\mathrm{~d})$ that stimulates CD8 $\mathrm{T}$ cells in insulin-dependent diabetes mellitus. Proc. Natl. Acad. Sci. U. S. A 99:5551-5556.

21. Wong, F.S., and Wen, L. 2003. The study of HLA class II and autoimmune diabetes. Curr. Mol. Med. 3:1-15.

\section{Tissue glycogen content and glucose intolerance}

\section{Masato Kasuga, Wataru Ogawa, and Takeshi Ohara}

Division of Diabetes and Digestive and Kidney Diseases, Department of Clinical Molecular Medicine, Kobe University Graduate School of Medicine, Kobe, Japan

J. Clin. Invest. 111:1282-1284 (2003). doi:10.1172/JCI200318526.

Insulin stimulates glycogen synthesis in the the liver and skeletal muscle. After a mixed meal, the secretion of insulin from pancreatic $\beta$ cells thus results in

Address correspondence to: Masato Kasuga, Division of Diabetes and Digestive and Kidney Diseases, Department of Clinical Molecular Medicine, Kobe University Graduate School of Medicine,

5-1 Kusunoki-cho 7-chome, Chuo-ku, Kobe 650-0017, Japan. Phone: 81-78-382-5860;

Fax: 81-78-382-2084;

E-mail: kasuga@med.kobe-u.ac.jp.

Conflict of interest: The authors have declared that no conflict of interest exists.

Nonstandard abbreviations used: glycogen synthase kinase-3 (GSK-3); protein phosphatase 1 (PP1); protein targeting to glycogen (PTG). about $20 \%$ and $30 \%$ of the carbohydrate intake being stored in the form of glycogen in the liver and skeletal muscle, respectively $(1,2)$. Defects in this process can therefore be a major contributor to postprandial hyperglycemia. Indeed, the glycogen contents of the liver and skeletal muscle are reduced in individuals with type 2 diabetes $(3,4)$.

Glycogen metabolism is controlled predominantly by the coordinated action of two enzymes, glycogen synthase and glycogen phosphorylase, both of which are regulated by phosphorylation and allosteric modulators. Insulin promotes the net dephosphorylation of both glycogen synthase and glycogen phosphorylase through the inhibition of protein kinases and the activation of protein phosphatases. Among the protein kinases, glycogen synthase kinase-3 (GSK-3) is thought to be an important target for insulin in its stimulation of glycogen synthase activity $(5,6)$. Among the protein phosphatases, protein phosphatase 1 (PP1) has been implicated in this action of insulin (6).

PP1 is an abundant protein serinethreonine phosphatase that is expressed in all compartments of eukaryotic cells. The catalytic subunit of PP1 thus interacts with a wide variety of targeting subunits that localize it to specific sites within the cell. A family of proteins that target PP1 to glycogen and thereby regulate its activity has been identified. These proteins include $\mathrm{G}_{\mathrm{M}}$ (PPP1R3), G (PPP1R4), PTG (protein targeting to glycogen or PPP1R5), and PPP1R6.

\section{Deletion of glycogen-targeting subunits of PP1 (PTG and $G_{M}$ ) in mice}

PTG was cloned as a binding protein of the catalytic subunit of PP1 by Saltiel and coworkers in 1997 (7). This protein 